\title{
An Epistemological Approach to Argumentation
}

\author{
Alvin I. Goldman
}

Rutgers

The State University of New Jersey

\begin{abstract}
The evaluation of arguments and argumentation is best understood epistemologically. Epistemic circularity is not formally defective but it may be epistemologically objectionable. Sorenson's doubts about the syntactic approach to circularity are endorsed with qualifications. One explanation of an argument's goodness is its ability to produce justified belief in its conclusion by means of justified belief in its premises, but matters are not so simple for interpersonal argumentation. Even when an argument's premises and conclusion are justified for a speaker, this justifiedness may not be transmissible to every hearer. Still, an epistemic approach is instructive. Arguing in enthymemes can be legitimate, e,g., because enthymemes can help produce justified persuasion in an audience that supplies the missing premises.
\end{abstract}

Résumé: L'évaluation des arguments et de l'argumentation est mieux compris du point de vue épistemologique. La circulaire épistemologique n'a aucun défaut formel, mais peut avoir un défaut épistemologique. J'appuis, avec des réserves, les doutes de Sorenson sur l'approche syntactic à la circulaire. Une explication de ce que fait bon un argument c'est son aptitude de produire une opinion justifiée dans sa conclusion par des opinions justifiées dans ses prémisses, mais ce n'est pas aussi simple dans le cas de l'argumentation entre deux personnes ou plus. Même si les prémisses et la conclusion d'un argument sont justifiées pour l'interlocuteur ou l'interlocutrice, il se peux qu'il y a des auditeurs ou auditrices pour qui elles ne sont pas jusitifiées. Quand même, une approche épistemique est instructive. Des arguments enthymemes peuvent aider à produire de la conviction justifiée dans un public qui fournit les prémisses manquantes.

Keywords: argument, argumentation, argument evaluation, enthymemes, epistemic circularity, Sorenson.

\section{Introduction}

This paper explores an epistemological perspective on argument and argumentation, and locates grounds for argument evaluation in epistemological terrain. The topic is confined to factual argumentation, and offers no treatment of practical argumentation. There is precedent for an epistemological approach in the work of Biro and Siegel (1992), Pinto (2001, chaps. 2-3), Feldman (1994), Govier (1992), and perhaps Blair and Johnson (1987). However, many grounds for an epistemo- 
logical approach to argument and argumentation have not yet been fully delineated, nor have all the intriguing complexities been probed. I endorse the idea that goodness of argument or argumentation is profitably viewed-perhaps best viewedfrom an epistemological perspective, but 1 also identify some tricky issues that arise in trying to formulate precise relationships between good argument and epistemic norms. Parts of the discussion focus on the personal (mental) use of arguments in reasoning or inference, and another part of the discussion focuses on the interpersonal use of arguments in public discourse. I do not claim exclusivity for the epistemological perspective on argumentation. Other approaches are also instructive. I make only the more modest claim that the epistemological approach is particularly fruitful and can provide a unified framework for studying many dimensions of (factual) argumentation.

Some brief terminological comments are in order. The term "argument" will be used here for the product, or perhaps content, of argumentation, usually, for a set of sentences, or a set of propositions that might be expressed by means of such sentences. One member of such a set is a conclusion and the other members (possibly null) are premises. The elements of an argument might be printed, uttered, or merely thought. "Argumentation", by contrast, will refer to the process or activity of producing or deploying such a complex object. A process of argumentation can be purely mental, in which case it is "inference", or it can be overt and public. In the latter case, argumentation is normally aimed at an audience distinct from the thinker or speaker. I do not claim that all argument or argumentation should be evaluated from exactly the same point(s) of view. Private or personal argumentation does not have the same aims, and hence is not subject to exactly the same standards, as public or interpersonal argumentation. Nonetheless, I suggest that the principal modes of evaluating arguments and argumentation-especially those modes of evaluation associated with the field of informal logic-are best reconstructed in epistemological terms.

\section{Epistemic Circularity}

An interesting type of argument defect has figured prominently in recent epistemology but has been largely overlooked by practitioners of informal logic. Theorists of informal logic and reasoning lavish much attention on a notorious cousin of this defect-viz., circularity - but the type of putative defect to which I refer has escaped their attention. The defect in question is epistemic circularity. This type of circularity differs from garden-variety circularity, in which an argument's conclusion also appears as one of its premises. Epistemologists nowadays call this familiar type of circularity "premise circularity", to mark it off from the epistemic variety.

What is epistemic circularity? It is best introduced by means of a standard example (Alston 1986, 1993). Suppose you are asked, or simply wonder to yourself, whether your visual faculty is reliable, i.e., usually produces true or accurate 
beliefs. To gather evidence on this subject you perform a series of experiments. You look at the table to see what is there. You see a bowl, and you form the belief that a bowl is on the table. You also notice, concurrently, that you have just formed, via vision, a belief that a bowl is on the table. So here is a visually formed belief and this belief is true (there is a bowl on the table). Chalk up a success for your visual faculty: one for one. You next inspect the utility closet. There you see a broom. Concurrently, you notice that you have just formed a belief that a broom is in the closet. So here is a second favorable case, another vision-formed belief that is true. In this fashion you construct a "track record" of your visual belief-forming faculty, and you draw an inference about it, as follows.

(TR) I had a visually-formed belief in the proposition that a bowl was on the table, and this proposition was true.

I had a visually-formed belief in the proposition that a broom was in the closet, and this proposition was true.

My vision is generally reliable.

Call TR a "track-record" argument, since it argues to a conclusion about one's visual faculty based on premises concerning that faculty's past track record.

Notice that TR does not suffer from premise circularity. Its conclusion does not reappear as a premise in the argument. Nonetheless, TR appears to suffer from some kind of circularity. It is assumed that someone who advances TRwhether directed at himself or others - uses or relies on his visual faculty to substantiate or verify each of the argument's premises, in particular, the second conjunct of each premise asserting that the specified belief was true.' If so, hasn't the user of the argument assumed or presupposed the truth of the conclusion in order to substantiate these premises? Isn't that a kind of circularity, an objectionable or vicious kind of circularity? Surely, if one tried to establish the trustworthiness of a witness by relying on that witness's own statement of his reliability, one would be open to a charge of circularity.

If TR is objectionable, as many philosophers hold, its illegitimacy is clearly of an epistemological character. No formal, syntactic, or structural characteristic of the argument seems to be at fault. As informal logicians sometimes say, it does not have an "illative" defect. A defender of a formal or structural approach to argument evaluation might reply that although the conclusion isn't displayed among the set of premises printed above, a more accurate rendition of the argument used would include the conclusion among the premises. Isn't a person who uses TR tacitly employing the conclusion as a premise? If so, the argument has the familiar structural sort of circularity, i.e., premise circularity. 
This reply is not compelling. We need not assume that a user of TR starts with a belief that his vision is generally reliable. He may never have been reflective enough to pose this question to himself, or to form a belief on the subject. He may have unreflectively used his visual faculty to form beliefs about the physical world without yet holding beliefs about this visual faculty (or about its reliability, at any rate), just as there are psychological or neuropsychological faculties we regularly use without knowing or believing anything about them. The user of TR does use and depend upon his vision in coming to believe the argument's premises. That reliance gives rise to the epistemic circularity of his reasoning or argumentation. But reliance on vision in "securing" the premises need not incorporate prior belief in the argument's conclusion.

What, exactly, does epistemic circularity consist in? Let us call faculties such as sight and hearing, plus methods and individuals on which one might rely for testimony, belief-forming "sources". Now assume that a belief based on a source $X$ is justified only if source $X$ is in fact a trustworthy source. Then, following William Alston (1993) and Michael Bergmann (forthcoming), we can say that an argument $\mathrm{A}$ is epistemically circular just in case the justifiedness of (some of) the user's beliefs in A's premises requires the truth of A's conclusion. The user of an argument like TR comes to believe its premises, we are assuming, by depending or relying on the very source that the conclusion says is trustworthy, or reliable. So the positive justificational status of his premise beliefs requires the trustworthiness of that very source. This is the sense in which the conclusion is "presupposed" by the premises. ${ }^{2}$ The user of an epistemically circular argument need not use the conclusion in the sense of believing it; he need only use the source that the conclusion discusses.

It is a matter of some controversy within epistemology whether epistemically circular arguments are always vicious. Some say yes (Vogel, 2000), others say no (Bergmann, forthcoming; Goldman, 1999; Stewart, unpublished). What is relevant here is that their status as acceptable or unacceptable is an epistemological matter. The central question is whether people can ever be justified in believing the conclusions of epistemically circular arguments as a result of employing the arguments in the indicated fashion, where the same source X, mentioned in the conclusion, is used in forming beliefs in the premises. Since the central question concerns justifiedness of belief, it is clearly an epistemological matter. It hinges on a variety of epistemological considerations that we cannot pursue here. The point is that in at least this case, a form or style of argument or argumentation must be evaluated in epistemological terms. So no full or complete theory of argument or argumentation can omit an epistemological strand.

We might extrapolate from this case, moreover, by saying that what makes a good argument good is its suitability for producing justified belief in its conclusion by means of justified belief in its premises. As we shall see below, this characterization of argument goodness is rather too simplistic, and needs qualification. None- 
theless, if it is on the right track, then good argument or good argumentation is fundamentally an epistemological matter.

\section{Premise Circularity}

Let us now explore the epistemological approach by turning to the standard form of circularity: premise circularity. Roy Sorenson (1991) argues against a syntactic approach to circularity and in favor of what he calls a "pragmatic" approach. His so-called pragmatic approach, however, seems close to what I am calling an epistemological one, because it hinges on rational persuasiveness. Sorenson argues that syntactic circularity-having the form " $\mathrm{P}$, therefore, $\mathrm{P}$ "-is not a sufficient condition for objectionable circularity or question begging. He presents many arguments of the form "P, therefore, $P$ " that he claims are not objectionably circular because they are "rationally persuasive" (p. 248).

Although I agree with the spirit of Sorenson's approach, which emphasizes the epistemic as opposed to the syntactic, I do not find all of his examples and discussion compelling. Let me start with an example where the discussion is instructive but not wholly dispositive. Consider the following argument:

(A-1) Some arguments are written in black ink.

Some arguments are written in black ink.

In syntactic terms A-1 clearly exemplifies the form, "P, therefore, P", and so under the syntactic theory it should be objectionably circular. Sorenson contends, though, that A-1 is rationally persuasive and therefore not circular (in a sense of "circular" that entails defectiveness). The assumption is, of course, that we have a displayed token of A-1 written in black ink. One can become rationally persuaded of the truth of A-1's conclusion by considering the displayed token. The argument is sound, and a person who doubted the conclusion could come to know it is true by considering the argument token, including, of course, its premise. So what is defective about it? Sorenson buttresses his case by drawing a distinction between "propositional" and "ontic" reasons for a conclusion, where an "ontic" reason refers to things a proposition is about (p. 253). He admits that A-1 provides an "ontic" reason rather than a "propositional" reason for its conclusion. But he holds that ontic reasons can rationally persuade, so he concludes that A-1 is not a defective argument. ${ }^{3}$

This assessment of the case is unpersuasive. A better way to think about the status of A-1 is to distinguish, as Sorenson does not, between the displayed argument and another argument a thinker might mentally deploy in reaching the indicated conclusion. The mental argument $I$ have in mind would refer to A-1 but would not be identical to it. Call this other argument A-2 and spell it out as follows: 
(A-2) The displayed argument, A-1, is written in black ink.

Some arguments are written in black ink.

A-2 consists of a singular proposition as its sole premise followed by an existential generalization of this premise as the conclusion. A-2 is rationally persuasive, or justification conferring. Justified belief in its premises can make one justified in believing its conclusion. Indeed, a reader of the displayed token of A-1 will be justified in believing the premise of A-2 in virtue of possessing perceptual evidence that $\mathrm{A}-1$ is an argument and is written in black ink. He can easily deduce the conclusion of A-2 from this premise, and thereby become justified in believing that conclusion. Finally, there is nothing circular about A-2: its conclusion does not appear as a premise. It is highly plausible that A-2 is what a reader would think to himself in reasoning to the indicated conclusion, and this mode of reasoning or inference is unobjectionable. Of course, the premise of A-2 refers to A-1, so A-1 does get appealed to in the reader's thought process. But, contra Sorenson, it is not clear that A-1 is the argument that licenses a reader in being persuaded of its conclusion. So Sorenson's claim that A-1 is not defectively circular is suspect. The apparent non-defectiveness of A-1, 1 submit, is attributable to the fact that $A$ 1 is easily confused with A-2. It is clear that a reader/inspector of A-1 can become rationally persuaded of A-1's conclusion, but not so clear that this is via an inference that uses A-1. So this example does not clearly identify a non-defective argument with the syntactic form ' $\mathrm{P}$, therefore, $\mathrm{P}$ '.

My treatment of this case highlights the role of argument in purely mental inference, as opposed to public discourse or dialectic. Those who definitionally restrict argument or argumentation to the dialectical sphere, who exclude it from the domain of thought or "movements of the mind" (e.g., the pragma-dialectical approach of van Eemeren et al. 1993, and Johnson 2000), deprive themselves of this natural account of Sorenson's example, in which argument figures in private thought.

I turn now to a different point raised by Sorenson's discussion, one that plays a less prominent role in his article as a whole. This point indicates that there is a more complex relationship between argument and epistemic evaluation than I have thus far hinted at. Consider this argument:

(B-1) Either ants spit or it is not the case that ants spit.

Either ants spit or it is not the case that ants spit.

Notice that the conclusion of this argument (as well as its premise) is a theorem of logic. Thus, says Sorenson, it can be validly derived even with no premises at all. If we started with a valid premiseless argument and added a premise to it, that would yield a valid single-premise argument whose premise is superfluous. Since we are free to choose any premise, Sorenson simply chooses the conclusion 
itself. The result, he intimates, is a perfectly acceptable argument despite the fact that its form is ' $\mathrm{P}$, therefore, $\mathrm{P}$ '.

Sorenson expands on the moral of B-1 as follows:

For [B-1] to work, it must be understood as an argument with a single, redundant premise. Relative to a solely rule-driven derivation, $[\mathrm{B}-1]$ is not circular. Yet $[\mathrm{B}-1]$ is circular relative to a derivation that makes essential appeal to the premise of [B-1]. As is common practice in logic textbooks, we should distinguish between arguments and proofs. Arguments are not identical to proofs because one argument usually has many alternative proofs of its conclusion. (p. 261)

What should we conclude from these remarks? It isn't wholly clear what Sorenson himself intends. But, drawing on Sorenson's remarks, I propose the following moral. Arguments per se cannot be classified as (objectionably) circular or non-circular. An argument is only circular or non-circular relative to a specified derivation. More precisely, it is derivations, or things akin to derivations (e.g., sequences of thought), that are circular or non-circular. Arguments, in the end, are not exactly the right kinds of entities to qualify for this "normative" status. The reason for this might be diagnosed as follows. Arguments per se have syntactic and semantic properties, like logical form and validity or invalidity. But these are not epistemological properties, whereas circularity (in a prejorative sense) is an epistemological property. Insofar as informal logic seeks to understand and identify circularity, it may not be arguments, precisely, that bear this property, but entities like derivations, or perhaps stretches of private and/or public argumentation. The latter entities are episodes or events that involve or deploy arguments, but they should not be identified with arguments. It is only these types of things that possess the requisite epistemological properties such as being rational or being suitable for producing rational, or justified, persuasion.

This line of thinking comports nicely with a causalist approach to belief justifiedness (Goldman 1979, 1986). According to causalism about justification, a belief is justified only if it is causally produced or sustained by a suitable cognitive process or method. It follows from this that a belief cannot qualify as justified simply in virtue of the holding of logical relations between its own propositional content and the contents of other beliefs held by the agent, even held justifiably. Justifiedness also depends on how the target belief is arrived at (or at least causally sustained). In other words, it is not true that the following conditions suffice for justifiedness: (1) there is some set of (premise) propositions $P_{1}, \ldots, P_{n}$, each of which you justifiably believe, (2) proposition $C$ is validly deducible from these P-propositions, and (3) you add proposition $\mathrm{C}$ to your stock of beliefs. It does not follow that your belief in $\mathrm{C}$ is justified, unless we make further assumptions to the effect that you arrive at your belief in $C$ by "basing" it on propositions $P_{1}, \ldots, P_{n}$, where the basing relation somehow involves an appreciation or grasp of the relationship between $C$ and $P_{1}, \ldots, P_{n}$. If, for example, you are oblivious to these believed propositions, and instead you base your belief on some frivolous consid- 
eration independent of them, your belief in $\mathrm{C}$ could easily be unjustified. Thus, inferential justifiedness depends on the reasoning process-a process of "personal" argumentation-that the believer undergoes. This is confirmed by our discussion of B-1, although B-1 is admittedly an unusual case.

\section{Good Argument and the Normative Guidance of Belief}

At the end of section 2, I advanced the suggestion that what makes a good argument good is its suitability to produce justified belief in its conclusion by means of justified belief in its premises. In other words, a good argument is one that can transmit justification from premises to conclusion (and justification vis-à-vis the premises does not require prior justification vis-à-vis the conclusion). This link between good argument and justified belief was intended as a (tentative) proposal for saying wherein the goodness of an argument consists. But the link can also be exploited, it appears, for another purpose. Epistemologists are often interested in the project of giving guidance for the formation of belief. Rules for the guidance of belief can be construed as rules that specify the beliefs that a cognitive agent is epistemically permitted to adopt. Such rules can in turn be understood as rules of justification, on the assumption that being justified in believing $P$ amounts to being epistemically permitted to believe it (see Goldman, 1986, chap. 4). Building on the link proposed earlier, it looks as if we can say the following: If argument $\mathrm{A}$ is a good argument, then someone who is justified in believing all of A's premises can also be justified in believing A's conclusion. Unfortunately, matters are more complicated than this.

First, as noted earlier, a person won't be justified in believing A's conclusion unless she appreciates or recognizes the connection between the premises and the conclusion, or sees how the conclusion can be derived from the premises. A second problem arises if $\mathrm{A}$ is a non-deductively valid argument. (I assume that some non-deductive arguments are good, though I won't try to specify which ones.) One problem here is that the attempt to transmit justification from premises to conclusion can always be blocked or defeated by other beliefs of the cognitive agent. In other words, non-deductive reasoning is defeasible. Ceteris paribus, I am justified in inferring that the outside garage light is on if I am justified in believing that I just flipped the light switch to the "on" position. But if I also believe that there is no bulb in the socket, I cannot justifiably infer that the light is on. Thus, we cannot say that justifiably believing the premises unconditionally licenses an inference to the conclusion. It depends on what else is in the agent's corpus of beliefs.

The problem might seem unique to the non-deductive case. Where a deductively valid argument is in question, can't we say that an agent is unconditionally permitted to infer the conclusion if she justifiably believes the premises and appreciates the argument's validity? No, this doesn't hold even in the deductive case (Harman, 1973; Goldman, 1986). Suppose Jane justifiably believes some propositions that logically entail $C$, and at time $t$ she notices that they entail $C$. However, $C$ is an observable matter, and at time $t$ she ostensibly observes not-C. So Jane is 
prima facie justified in believing not-C. Is she still justified in inferring $\mathrm{C}$ from the other propositions that entail it? That is doubtful. It seems more reasonable of Jane to retract belief in one or more of the entailing propositions. So formulating a precise relationship between the goodness of an argument and the transmissibility of justification from premises to conclusion is not a simple matter. This complexity is not a reason to abandon the view that goodness of argument is an epistemological matter, but it isn't a simple epistemological matter.

\section{Interpersonal Argumentation and Epistemic Norms}

Thus far I have considered only personal uses of arguments. Obviously, a great deal of argumentation consists in the public presentation of arguments: presentations aimed at audiences beyond the speaker or writer alone. Theories of argumentation rightly deal with this domain of public argumentative discourse. Are there norms for interpersonal argumentation, and if so what is their relationship to norms of intrapersonal argumentation? Are there epistemic norms pertaining to interpersonal argumentation, and if so what are they like?

There are two roles to consider in argumentative discourse, those of speaker and hearer. For starters, what can be said about hearers? Consider a hearer who receives an argumentative discourse from a speaker, a single, endorsed argument. The initial response of the hearer is to operate as a reasoner and decide whether to accept the argument's conclusion, or how much credence to place in it. Subsequently, the hearer might assume the role of speaker and verbally respond to the argument, but first he must decide how to respond to it credally. What should he do? Approaching the matter epistemically, a central question is how the presented argument affects the hearer's justificational status vis-à-vis the argument's conclusion. In a typical situation, the speaker aims to persuade her hearers of the conclusion. But should the hearer be persuaded, epistemically speaking? Is a "good" piece of interpersonal argumentation automatically suited to persuade a random hearer?

The situation is more complicated than that of intrapersonal argumentation. Suppose the speaker justifiably believes his argument's premises. Whether the hearer will also be justified in believing them, after hearing them endorsed by the speaker, is an open question. Some epistemologists of testimony say that testimony is a fundamental source of prima facie justification, so that a hearer is prima facie justified in believing any random speaker's assertions. Even if true, this yields only prima facie justification. A hearer might have reasons to distrust the speaker concerning these very premises, reasons pertaining to the speaker's sincerity or competence. These reasons may keep the hearer from being ultima facie justified ("all-things-considered" justified) in accepting the premises from the speaker, even though the speaker justifiably believes them. Furthermore, the hearer might have reasons unrelated to the present speaker for doubting the truth of the premises. If, for any of these reasons, the hearer isn't justified, all things considered, in accepting the argument's premises, then she won't be able to acquire 
justification vis-à-vis the conclusion from the speaker's argumentation. In short, however justified the speaker may be with respect to the argument's premises and conclusion, a hearer's justifiedness is yet another matter. A speaker's justifiedness is not automatically transmissible to the hearer. In favorable circumstances, on the other hand, such transmissibility is certainly possible. This is exactly what a sincere speaker hopes to accomplish with respect to his audience. He hopes he is justified with respect to the premises and conclusion of his argument, and he hopes that by presenting that argument to the audience, all or some of them will become justified with respect to the premises and conclusion-especially the conclusion-and will therefore believe them.

I turn now to norms that might govern a speaker's argumentative behavior. Some of these norms are fairly straightforward (see Goldman, 1994; Goldman, 1999, chap. 5). For example, a speaker should not assert the premises of an argument he defends unless he justifiably believes those premises. Nor should he assert an argument's conclusion unless he justifiably believes that it is well supported by premises he justifiably believes.

There are other plausible norms for speaker argumentation that can best be understood in terms of epistemic desiderata. First, consider a norm concerning the presentation of enthymemes, by which I mean arguments with unexpressed premises. ${ }^{4}$ Enthymematic arguments are hard to justify or explain, yet it is undeniable that ordinary argumentative discourse is replete with enthymemes. How is this to be explained, and is it defensible?

It is readily explained and defended if the usual aim of argumentative discourse is to generate in hearers newly justified beliefs in the conclusion. In assessing a conclusion's plausibility, the hearer of an argument does not rely exclusively on the speaker's stated premises. A thoughtful hearer will marshal all relevant evidence at her disposal, at least all evidence that readily comes to mind. Suppose that evidence $E$ is highly relevant to the speaker's conclusion, and would be appropriate to include as a premise in his argument. But, as the speaker realizes, $\mathrm{E}$ is also widely known in the discursive community. Then the speaker may be entitled to assume that his audience knows $\mathrm{E}$ and that they would think of it in contemplating his proffered conclusion. Why, then, should he bother to mention it? Conversational efficiency dictates otherwise and epistemic considerations concur. Hearers will use $E$ to assess the conclusion whether the speaker mentions it or not, and their justification vis-à-vis the conclusion will be the same even if he omits it. There will be no loss in epistemic import. When it is recognized that the standard aim of argumentation is to produce justified persuasion in the audience, it does not matter if parts of the persuasion and the justifiedness have sources other than the current argument as spoken (or written). Thus, it is easy to make sense of arguing in enthymemes when we adopt an epistemological perspective.

A second type of argumentative norm concerns responses to anticipated objections. Commentators on argumentation sometimes consider it a norm for a 
speaker to respond to criticisms anticipated from his hearers, even before they actually lodge those criticisms. Anticipation of objections, especially widely known objections, is the mark of high-quality argumentation. Why should this be so? Again, it is easily explained from an epistemological perspective. If the presumptive aim of argumentative discourse is to generate newly justified beliefs in the minds of an audience, then it makes sense to present and try to rebut anticipated objections. Anticipated objections are premises or arguments that audience members are disposed to think of on their own and to treat as defeaters to the justification that the speaker's argument aims to confer on his conclusion. Unless these defeaters are themselves defeated, members of the audience will not be justified, all things considered, in believing the speaker's conclusion. At least they won't think that they are justified. Thus, they are unlikely to believe the conclusion, or believe it justifiably. Since justified belief in the conclusion is, by hypothesis, the (or $a$ ) presumptive aim of argumentative discourse, anticipatory replies to objections, especially prevalent objections, is a good-making feature of argumentative discourse.

Ralph Johnson (2000) offers a different account of the normative requirement that speakers respond to objections, including anticipated objections. Johnson's explanation is that it is essential to argumentation that it not only be rational but "manifestly" rational. Argumentation must have the appearance of rationality, just as a judge must not only be fair-minded but must give the appearance of fairmindedness (Johnson 2000, pp. 163-164). We don't need to postulate this extra layer of "appearance" to explain objection-responsiveness. Indeed, I think it's a mistake to do so. I don't believe there is a norm that arguers should respond even to poor or ineffective objections simply for "show". If a criticism does not qualify as a defeater of his argument, and if the criticism would not be mistaken for a defeater by the critics, then the arguer need not respond to it. Of course, almost all objections are believed to be defeaters at least by their proponents; otherwise, they would not be prepared to pose them. But since the presumptive goal of argumentation, on my favored approach, is to produce justified belief in the conclusion on the part of the audience, and since even believed defeaters will preclude adoption of the conclusion unless the believed defeaters are defeated, the arguer had better respond to them. Thus, we don't have to take recourse in a desire to maintain "appearances" to make sense of argumentative norms.

\section{Justification and Truth}

The main epistemological concept I have appealed to in my account is the notion of justification. In previous work, however, especially Knowledge in a Social World (Goldman, 1999; also see Goldman, 1994), I interpreted norms of argumentation in terms of another epistemic goal: the goal of truth (true belief). What is the relationship between the present, justification-oriented discussion and my earlier, true-belief oriented treatments? 
The relationship is pretty straightforward. On the account of justification I favor, and on many other existing accounts as well, justified belief has an intimate link to true belief. A justified belief has properties (specifically, its source or manner of production) that make it likely to be true, at any rate, more likely to be true than an unjustified belief in the same sort of content. Thus, a practice of argumentation that is well aimed at the goal of producing justified belief in a hearer will also be well aimed at the goal of producing true belief in a hearer. Now, true belief-or "knowledge" in a weak sense of the term-is something people value, either for its own sake or for the sake of its capacity to help one achieve other goals. Given the value people place on knowledge or information, it is not surprising that there should be a social practice of exchanging information and exchanging evidence that supports informative claims, so that people may profit from one another's knowledge. The social practice of argumentative communication, as I see it, is part of a larger cooperative practice of information sharing (cf. Grice, 1989). This larger picture I propose places argumentation in a setting that is closely linked to what is epistemically valued: justified belief and knowledge. I think this is the most fruitful direction from which to approach the subjects of argument and argumentation.

\section{Notes}

'It would be possible to substantiate the second conjuncts of the premises by a method other than vision, for example, by hearing other observers verbally testify to the truth of the specified beliefs. Under that scenario, epistemic circularity would not be an issue. However, that is not a scenario under discussion here. I restrict attention to the scenario in which only vision is used to establish the premises (at least the second conjuncts of the premises - the first conjuncts being established by introspection).

2 My use of the term "presuppose" is deliberately casual; I do not mean to invoke any of the senses of the term that theorists of presupposition have proposed.

3 Aversion to ontic persuasion, Sorenson remarks, is a symptom of "validity chauvinism", which he rejects (p. 253).

"I do not mean by "enthymeme" a deductively valid argument with unexpressed premises. That seems to be the "traditional" idea of an enthymeme, as found in Aristotle"s Rhetoric (II.2.1357a1722) and in Quine's Methods of Logic (1972, p. 169). Hitchcock (1998) argues that the traditional conception of the enthymeme is too narrow, on the grounds that there are respectable arguments not involving inductive or ceteris paribus inferences that are also not deductively valid. I do not mean to take sides on this issue.

\section{References}

Alston, William (1986). "Epistemic Circularity," Philosophy and Phenomenological Research 47: 1-30.

Alston, William (1993). The Reliability of Sense Perception. Ithaca: Cornell University Press.

Bergmann, Michael (forthcoming). "Epistemic Circularity: Malignant and Benign," Philosophy and Phenomenological Research. 
Biro, John and Siegel, Harvey (1991). "Normativity, Argumentation and an Epistemic Theory of Fallacies," in F. H. van Eemeren, R. Grootendorst, J. A. Blair, and C. A. Willard, eds., Argumentation: Across the Lines of Discipline (pp. 189-199). Dordrecht: Foris.

Blair, J. Anthony and Johnson, Ralph H. (1987). "Argumentation as Dialectical," Argumentation 1: 41-56.

Feldman, Richard (1994). "Good Arguments", in F. Schmitt, ed., Socializing Epistemology: The Social Dimensions of Knowledge (pp. 159-199). Lanham, MD: Rowman \& Littlefield.

Goldman, Alvin (1979). "What Is Justified Belief?" in G. Pappas, ed., Justification and Knowledge (pp. 1-23). Dodrecht: Reidel.

Goldman, Alvin (1986). Epistemology and Cognition. Cambridge, MA: Harvard University Press.

Goldman, Alvin (1994). "Argumentation and Social Epistemology, "Journal of Philosophy $91: 27-49$.

Goldman, Alvin (1999). Knowledge in a Social World. Oxford: Oxford University Press.

Govier, Trudy (1992). "What Is a Good Argument?" Metaphilosophy 23: 393-409.

Grice, Paul (1989). Studies in the Way of Words. Cambridge, MA: Harvard University Press.

Harman, Gilbert (1973). Thought. Princeton: Princeton University Press.

Hitchcock, David (1998). "Does the Traditional Treatment of Enthymemes Rest on a Mistake?" Argumentation 12: 15-37.

Johnson, Ralph H. (2000). Manifest Rationality: A Pragmatic Theory of Argument. Mahwah, NJ: Erlbaum.

Pinto, Robert C. (2001). Argument, Inference and Dialectic. Dordrecht: Kluwer.

Quine, Willard V. O. (1972). Methods of Logic, $3^{\text {rd }}$ edition. New York: Holt, Rinehart and Winston.

Sorenson, Roy (1991). "'P, therefore, P' without Circularity," Journal of Philosophy_88: 245-266.

Stewart, Todd (unpublished). "Coherentism and Epistemic Circularity," manuscript, Department of Philosophy, Illinois State University.

van Eemeren, Frans, Grootendorst, Rob, Jackson, Sally, and Jacobs, Scott (1993). Reconstructing Argumentative Discourse. Tuscaloosa, AL: University of Alabama Press.

Vogel, Jonathan (2000). "Reliabilism Leveled," Journal of Philosophy 97: 602-623.

Alvin I. Goldman

Department of Philosophy

Rutgers. The State University of New Jersey

26 Nichol Avenue

New Brunswick. NJ 08901

goldman@philosophy.mugers.edt 